\title{
Leaders
}

\section{"Living high and training low" can improve sea level performance in endurance athletes}

The use of altitude training to augment sea level endurance performance is widely practiced by athletes and coaches. Scientific evidence confirming the efficacy of this practice is sparse, some would argue, lacking. Further, the mechanisms responsible for the effect have not been elucidated. We have performed a series of carefully controlled studies that show that altitude training can improve sea level endurance performance, above and beyond good sea level training, when certain conditions are met. If potential pitfalls are avoided and the athlete lives high enough for long enough, he or she will increase red cell mass, and if he or she trains low enough to maintain normal training velocities and oxygen flux, the athlete will enjoy an improvement in subsequent sea level performance.

We recruited 39 college runners to train together in Dallas, Texas, USA for four weeks, and the runners achieved a substantial $(2.1 \%)$ improvement in $5000 \mathrm{~m}$ time trial performance from a "training camp" effect. Then the group was randomly divided into three equivalent subgroups based on their last performance. Each group consisted of nine male and four female runners and the groups were designated HiHi, HiLo, and LoLo. The HiHi and HiLo groups lived together for four weeks at $2500 \mathrm{~m}$ in Park City, Utah, USA while the LoLo group travelled to the US Olympic Training Center in Chula Vista, California for sea level living and training for the same period of time. The HiHi group performed typical altitude training in and around their living altitude while the HiLo group travelled down twice a day for near normoxic training in and around Salt Lake City. Training volume, relative intensity, weather, and terrain were similar between the sites. Both $\mathrm{HiHi}$ and HiLo groups increased red cell mass and maximal oxygen uptake while there were no changes in the LoLo group. Only the HiLo group showed further $5000 \mathrm{~m}$ time trial improvement on return to Dallas. In response to four weeks of living at $2500 \mathrm{~m}$ and training around $1300 \mathrm{~m}$, the HiLo group data showed a $1.4 \%$ improvement in performance immediately on return to sea level and for up to three weeks thereafter. ${ }^{1}$ Our data indicate that this was due to an enhanced red cell mass while velocity and oxygen flux during training were maintained. The $\mathrm{HiHi}$ group did not improve because of significantly reduced training velocities and oxygen flux, and the LoLo group did not improve because they had no enhancement of red cell mass although they were able to maintain training velocities. To put this in perspective, the average HiLo athlete was now at the finish line, when, he/she, before the HiLo camp, and the current competitors (HiHi and LoLo) still had about 100 $\mathrm{m}$ to go.

However, there was considerable variation among athletes in each group, with some individuals enjoying a $5 \%$ improvement and others not improving sea level endurance performance. In a subsequent study, ${ }^{2}$ including additional runners, we attempted to elucidate reasons for these differences between individuals.

The mechanism for the improvement is an increase in maximal oxygen uptake produced by an increase in oxygen delivery to working tissues from an increase in red cell mass. Erythropoietin stimulates stem cells in the bone marrow to multiply and differentiate toward the red cell line. Although incompletely characterised, in rats $^{3}$ and probably humans, ${ }^{2}$ renal parenchymal oxygen tension and arterial oxygen content determine the magnitude of erythropoietin production. The altitude that produces a sufficient decrease in renal parenchymal oxygen tension to produce a robust and sustained increase in circulating erythropoietin levels varies between individuals. We speculate that some individuals may increase red cell mass while living at altitudes of $2000 \mathrm{~m}$, whereas others may need to live close to $3000 \mathrm{~m}$. Our group data indicated that living at $2500 \mathrm{~m}$ for four weeks increased mean red cell mass by $9 \%$, which resulted in a $5 \%$ increase in maximal oxygen uptake. ${ }^{1}$ The individuals that increased red cell mass improved maximal oxygen uptake.

The effect of increased red cell mass on performance can be tempered by reduced power during workouts, particularly higher intensity workouts. Similar to the erythropoietic response, there is a wide variation among athletes in the ability to maintain near normal training velocities and oxygen flux at altitude. Those individuals who are able to maintain normal training velocities and oxygen flux during interval workouts are able to make use of the improvement in maximal oxygen uptake and improve subsequent sea level performance. ${ }^{2}$ The athlete that experiences greater desaturation in arterial blood during high intensity work at sea level is likely to have a greater impairment than his peers during training and racing at moderate altitudes.

The desaturation that occurs during exercise at moderate altitude reduces the power output during training, and, for the well trained athlete, this results in relative detraining. The degree of arterial desaturation during exercise does not correlate with the vigor of the erythropoietin response to living at altitude. Thus the erythropoietic response to living in hypoxia is a different characteristic from degree of desaturation during exercise.

Several factors may interfere with an otherwise positive response to an altitude sojourn. Iron deficiency prevents an increase in red cell mass. ${ }^{4}$ We estimate that iron is used at ten times the normal rate and must be available to increase red cell mass, either in normal bone marrow stores or by aggressive supplementation, or both. Concurrent infection may moderate the hypoxic stimulus because of the production of cytokines that inhibit erythropoietin production and direct the bone marrow to produce white cells. Acute traumatic injuries must also be avoided to maintain the training stimulus as well as avoid production of inhibitory inflammatory cytokines. Attention must be paid to the correct training intensities, as athletes' cues for appropriate training intensities are altered at altitude. Adequate intake of fluid is necessary to minimise the dehydration associated with the greater renal, respiratory, and dermal water losses at altitude. An adequate intake of dietary carbohydrates and proteins is important to replace glycogen stores and rebuild tissues used during an altitude sojourn.

Our studies involved both male $(\mathrm{n}=89)$ and female $(\mathrm{n}=$ 37) athletes. When the pitfalls are avoided, the genders respond similarly. However, two thirds of the female runners we have studied have been iron deficient and some 
have had disordered eating patterns. Thus extra care must be taken to ensure adequate nutrition and iron availability for female athletes considering an altitude sojourn.

Our original studies were performed on American university varsity runners. They are accomplished athletes, but the group would not be considered elite. In addition, we studied them during summer when they may not have been at their peak of fitness for the year. To be able to generalise our results further, we studied a group of 27 elite American middle and long distance runners after they had completed the NCAA Championships or the USA Track and Field National Championships. The National Championships also served as tryouts for the IAAF World Championships, ensuring peak levels of fitness before the HiLo camp. After living for four weeks at $2500 \mathrm{~m}$ and performing high intensity training at $1300 \mathrm{~m}$, the group improved $3000 \mathrm{~m}$ time trial performance by $1.2 \%$. $^{5}$ The changes in haemoglobin concentration, maximal oxygen uptake, and running performance of the elite men and women were essentially identical with that obtained with the university runners. Thus we believe that our data can be generalised to all levels of endurance sport.

The hypoxia associated with training for four weeks at low altitudes (1250-1750 m) did not alter skeletal muscle histochemistry or biochemistry in our studies. ${ }^{6}$ Capillary density and activities of marker enzymes for glycolysis, fatty acid utilisation, and oxidative metabolism were unchanged after training at either low or moderate altitudes. Similarly there were no improvements in tissue buffer capacity or oxygen deficit from training under conditions of mild to moderate hypoxia. Myoglobin levels are unchanged by these perturbations. Indeed, improvement in sea level endurance performance seemed to be associated with maintenance of normal rates of oxygen transport. These data suggest that maintaining oxygen availability to the tissues is the critical component required to avoid negative effects on the ability of skeletal muscle to perform high intensity work on return to sea level.

\section{Cricket: injury in long trousers}

Cricket returns to centre stage (some of the England team must feel they have never been off it!) on 14 May with the 1999 Cricket World Cup. England play the holders, Sri Lanka, at Lords in the tournament's opening match. It ends 41 matches later with the final, again at Lords, on 20 June. England will play nine games to get there and in some ways this encapsulates the changing face of international cricket: as many tests as always, a lot more high intensity one day internationals, with the season extended through 12 months of the year.

The time for rest and recuperation is minimal, and overuse has become the major scourge of our elite cricketers. It is not only the elites who suffer. Our promising adolescent fast bowlers, with commitments to school, club, county, and country will spend most of their summer holidays bowling on a daily basis, and the epidemic of pars stress fractures in adolescence is well established. ${ }^{1}$ Crucially the drop out rate in the United Kingdom is not known, but the Australians are concerned (Twoomey L, personal communication) and highlight the numbers of promising fast bowlers in schools (plenty), in the academies (some), and at elite level (few). It is encouraging to see the England and Wales Cricket Board (ECB) following the example of the Australian Cricket Board (ACB) in issuing bowling
An extension of these findings has been the creation of hypoxic environments in which to live at sea level, which can be easily emerged from for training. The reduction in the number of oxygen molecules in a given litre of air is achieved by either adding nitrogen or reducing the barometric pressure. A significant problem with these technologies is the length of time spent under hypoxic conditions within a 24 hour period and the number of weeks spent in that environment. Suppression of erythropoiesis during the time in normoxia may negate any stimulation of erythropoiesis gained from the time spent in the hypoxic environment.

In summary, our data show that if a healthy endurance athlete with normal iron stores lives high enough (2000 to $3000 \mathrm{~m}$ ) for long enough (three to four weeks) to produce a robust and sustained increase in erythropoietin, he or she will achieve an increase in red cell mass. This increase in red cell mass will produce an increase in maximal oxygen uptake, which, as long as training velocities and oxygen flux are maintained, will result in an improvement in subsequent sea level performance.

JAMES STRAY-GUNDERSEN BENJAMIN D LEVINE

Norwegian University of Sport and Physical Education

1 Levine BD, Stray-Gundersen J. "Living high-training low": the effect of moderate altitude acclimatization with low altitude training on sea level performance in trained runners. F Appl Physiol 1997;83:102-12.

2 Chapman RF, Stray-Gundersen J, Levine BD. Individual variation in response to altitude training. $\mathcal{F}$ Appl Physiol 1998;85:1448-56.

3 Ou LC, Salceda S, Schuster SJ, et al. Polycythemic responses to hypoxia: molecular and genetic mechanisms of chronic mountain sickness. F Appl Physiol 1998;84:1242-51.

4 Stray-Gundersen JC, Alexander A, Hochstein D, et al. Failure of red cell volume to increase to altitude exposure in iron deficient runners. Med Sci Sports Exerc 1992;24:S90.

5 Stray-Gundersen J, Chapman RF, Levine BD. HiLo altitude training improves performance in elite runners. Med Sci Sports Exerc 1998;30:S35.

6 Stray-Gundersen J, Bertocci L, Levine BD. Effects of low or moderate altitude training on skeletal muscle. Med Sci Sports Exerc 1999;31:S00.

prescription guidelines for both practice and match play for a given age. Twelve month ECB contracts for the elites will help, as will heightened awareness among players, coaches, and parents of the perils of bowling too fast for too long. ${ }^{2}$ Injury prone bowling techniques are now well established, ${ }^{3}$ and technique alterations should be used primarily as a proactive measure early in a fast bowler's career (bowl front-on or side-on but do not mix the two), and the pitfalls of changing technique in reaction to back injury, with or without surgery, are not inconsiderable, not least in loss of form.

It has been immensely refreshing to watch the ECB and their medical team grasp these concepts and move away from an overdependence on imaging, the needle, and the knife. Focus on these and the fundamental roles of overuse and incorrect technique in the aetiology of cricket injury become somewhat obscured. They end up as an alternative, rather than an adjunct, to adequate rehabilitation. The players themselves are increasingly aware of what is on offer. Some took advantage of Pilates classes during the winter tour, recognising the benefits of core stability training in both the prevention and treatment of injury. The sports medicine specialist is uniquely placed to "gatekeep", guiding the players through the myriad of treatment 
modalities available to them, some effective and some not, while avoiding the temptation to opt for the quick fix that time constraints render so attractive.

Asked recently what billiards, bowls, cricket, curling, golf, and riflery have in common, I immediately replied that they were all sports played in long trousers. In fact they were all grouped as low static low dynamic types of exercise by sport at the 26th Bethesda Conference of 1994 (a consensus meeting of cardiologists, sponsored by the American College of Cardiology and the American College of Sports Medicine) ${ }^{4}$ aimed at athletes with known cardiac disease such as hypertrophic obstructive cardiomyopathy (HOCM). Perhaps this encapsulates a problem that our fast bowlers face, and yet they operate at about $80 \%$ of maximum heart rate for most of their spell with vertical ground reaction forces at front foot impact of up to nine times body weight.

Whether I choose billiards or fast bowling for any child of mine with HOCM is an irrelevance, but knowing your sport is not. Spare a thought then for the likes of Fraser, Mullally, and Gough just returned from an Ashes series and a four month tour of Australia and soon to depart for Sharja for a one day tournament through to the World Cup in May/June, followed by a test series against New Zealand, the tail end of the county cricket season, and departure in October for a winter in South Africa. And maybe some billiards to relax in between!

Clinical Director, Sports and Orthopaedic Medicine, Barbican Health

Congeni J, McCulloch J, Swanson K. Lumbar spondylolysis. Study of natural progression in athletes. Am 7 Sports Med 1997;25:248-53.

2 Bell P. Spondylolysis in fast bowlers: principles of prevention and a survey of awareness among cricket coaches. Br f Sports Med 1992;26:273-5.

3 Elliot B, Burnett A, Stockhill N, et al. The fast bowler in cricket: a sports medicine perspective. Sports, Exercise and Injury 1995;1:201-6.

4 Mitchell JH, Haskell WL, Raven PB. et al. Classification of sports: 26th Bethesda Conference: recommendations for determining eligibility for competition on athletes with cardiovascular abnormalities. $f$ Am Coll Cardiol 1994;24:864-6.

\section{Seeking misclassification: "doping" in disability sport}

Disability sport has grown in this country from the early Stoke Mandeville Games set up by Sir Ludwig Guttmann to the elite international level it is today. ${ }^{1-3}$ Excellent work has gone into the development of classification systems that are accepted by the International Paralympic Committee, and new ways of improving the system are always under review. However, what happens when an athlete is determined to obtain an inappropriate classification? This is the disability sports equivalent of doping, because the athlete is trying to achieve a performance level that is not within his or her normal physiological range of performance in that class. Misclassification is an attempt to achieve an unfair advantage over other competitors by either wilfully increasing a functional deficit or somatising subconsciously a psychological problem.

The classification system ${ }^{45}$ itself was developed to allow athletes with different physical disabilities to compete against each other in classes when they have the same functional disability. In swimming, for example, the athlete performs a bench test followed by a functional water mobility test, and two independent international experts assign the classification. These experts are a medical professional such as a physiotherapist and a technical expert. There are two tests because, for example, someone with cerebral palsy may perform badly when walking but find the movements and the buoyancy of the water more helpful than another athlete on dry land. In the last 18 months I have seen disabled athletes try to "maximise" their symptoms and signs of disability with the hope of getting selected. This may seem a perverse statement to make in disability sport: that to win you need to be more disabled. However, consider the system. If an athlete appears more disabled than he or she really is, he or she is put in a more disabled (functionally disabled) class and so is more likely to beat his or her opponents.
The team doctor normally has to maintain a distance from the classification procedure or else confidentiality and the trust of the athlete could be lost. However, there are occasions when this is a very delicate balancing act.

The pressure on disabled athletes to perform has increased now that most sports are under the auspices of their able bodied counterparts. Lottery money has exposed serious divisions between sports and increased the pressure on athletes in the World Class Performance Plan. The sport is no longer for rehabilitating disabled people, but is a serious elite international business with all the problems that that can bring. There is no place for "do-gooders" who feel "sorry for the poor disabled". These are extremely competent elite athletes with staggering world record times. Psychological testing of 120 athletes from individual sports showed no differences from their able bodied counterparts. ${ }^{6}$

Truly disabled athletes must be protected from those who consciously or subconsciously try to be disabled to represent their country. It is of enormous importance to have highly trained classifiers, physiotherapists, and medical staff along with vigilant team managers. It is the ability not the disability of the person that is looked for and encouraged.

F Y FIRTH

Team doctor of the British Paralympic Association

1 Arbuthnott K. Sport for people with a disability: the current state of play. $\mathrm{Br}$ f Sports Med 1998;32:275-276.

2 Jackson RW, Friedericksen A. Sport for the physically disabled: the 1976 Olympiad (Toronto). Am F Sports Med 1979;7:293-8.

3 Clark MW. Competitive sports for the disabled. Am $f$ Sports Med 1980;8:366-9.

4 Meaden CA. Assessment of people with a disability. London: Disability Sport England Office, 1990

5 Mahoney FI, Barthel DW. Functional evaluation (ADL): the Barthel index; rehabilitation notes. Maryland State Medical fournal 1985;Feb:61-4.

6 Firth FY. The motivational orientation of elite disabled athletes and the relationship to trait anxiety. PhD Thesis, 1998. 


\section{Boxing and medicine}

\author{
Boxing damages your brain: don't let anyone tell you \\ different $^{1}$ \\ Barry McGuigan
}

A vagary of the law in the United Kingdom is that no offence to a boxer is committed during a fight because both parties have agreed to it and the validity of the contest is beyond question if sanction is given by the British Boxing Board of Control. The latter depends for its authority on the involvement of doctors. The legality of boxing depends on some puzzling public policy decisions. ${ }^{2}$

Historically the judgment in $\mathrm{R} v$ Young and Others, 22 November 1866 in the Central Criminal Court before Bramwell B ties doctors to boxing. John Young and others were indicted for feloniously killing and slaying Edward Wilmut. On 9 October, Young and Wilmut naked to the waist, wearing gloves, boxed each other in a room where there was a ring, one side of which was formed by one side of the room and the other by ropes. The others acted as seconds or were there as spectators. They then fought a succession of rounds, sparring and hitting each other as hard as they liked with gloves for upwards of one hour. At the last round Wilmut fell, either from a blow or a shove from Young, and struck his head against a post which ran in the centre of the ring. He died five hours later at Charing Cross Hospital. The evidence of George Airy, the House Surgeon at Charing Cross Hospital, showed that the deceased died from a rupture of an artery in the brain caused by a bruise over the right ear which might have been caused either by a blow or a fall. Bramwell $\mathrm{B}$, in his summing up, placed great emphasis on the evidence of Dr Airy and stated "but the medical witness here had stated that this sparring with gloves was not dangerous and not a thing likely to kill". ${ }^{3}$ The defendants were found not guilty. This initial decision, followed by the dicta in $\mathrm{R} v$ Coney $^{4} 1882$, has given rise to the special situation which allows the sport of professional boxing to be removed in practice from the assault provision in the Offences Against the Person Act 1861. The fact that the evidence of Dr Airy was what clearly persuaded the jury to return the verdict of not guilty in $\mathrm{R} v$ Young was the first instance in the continuing relationship between boxing and medicine.

For those who oppose boxing, the sport is exploitative, repulsive, and without any worth, beyond satiating the blood lust of its spectators. On the other hand, supporters of the sport believe it to be an exhilarating exhibition of skill between, for the most part, two highly trained, physically comparable, and skilled athletes. As well it is claimed to provide an avenue to prosperity for a section of the population who are disadvantaged because of social class and lack of education. These two points of view are clearly set at the extreme ends of the argument and there is rarely a middle ground to be found when commenting on the sport. Boxing is unequivocally a dangerous sport. There is ample evidence that boxing can and does cause brain ${ }^{5}{ }^{6}$ and eye $^{7}$ damage.

One polar opposite view is as expressed by Kevin Wildes, Assistant Professor of Philosophy, Georgetown University in Boxing and medicine that in a multicultural postChristian morally pluralistic society it would be wrong to ban boxing, as the society in which we live no longer shares a common moral culture or even a common moral language. Wildes responds to those who favour banning boxing on the grounds that the intention is to cause serious injury by suggesting that this argument fails, for in a normally pluralistic society there are different views on what constitutes uncivilised and immoral behaviour and there is no universal moral stance that allows society to make such an evaluation of boxing. The dilemma for the medical practitioner is an ethical one. Does he accept the moral stance of the liberal pluralist society? This views the harm due to boxing as being less important than the loss of individual freedom and autonomy that would result if the sport were banned, and places great emphasis on the fact that the professional boxer voluntarily consents to take part in the sport. Or does the practitioner accept that the inevitable damage caused by boxing transforms the ethical question into an absolute moral imperative?

Interestingly, although the most venomous attacks on boxing arise on both sides of the Atlantic from the British Medical Association and the American Medical Association, neither has put their anti-boxing views to a vote of their membership. No practitioner would be surprised at this moral paralysis. Of course, for those of us who practice medicine in the real world the question is: is a boxer's health improved and the prospects for his survival increased by the presence of doctors at the ringside?

Boxing authorities acknowledge the importance of doctors' involvement and readily and willingly introduce new regulations and procedures when medical advisors so recommend. All the world governing bodies of the sport have doctors in their membership to advise on the safety aspects of boxing.

The World Boxing Council Medical Congress (Aruba, May 1997) made 56 recommendations and suggested nine research studies, all aimed at making professional boxing safer. The doctor's involvement with boxing is crucial both to improve safety and to ensure the continuation of the sport. All those involved in boxing are fully aware of the dangers of the sport and are constantly revising the medical regulations in an effort to make it safer.

The British Boxing Board of Control is a voluntary, self elected, and self perpetuating body, the jurisdiction of which is not founded on statute. Perhaps more confidence would exist if the Board were given some statutory status to oversee both amateur and professional boxing. The Boxing Board hopes that Parliament will at sometime recognise the desirability of a disciplined and tightly supervised sport.

A ban on boxing is unlikely even in this "nanny" state, but, within the clearly recognised parameters that strong fit men-and now women-will injure each other, this damage can and must be limited and its effects responded to appropriately and urgently by doctors continuing to be involved with boxing. The practitioner's commitment to the sport at the two levels-namely, regulatory and at ring side, will result in further and significant regulation and rule changes.

G O’NEILL

British Boxing Board of Control

\footnotetext{
1 Hughes R. The samurai deep in the soul of McGuigan. Sunday Times 1988 April 17;sect A:21

2 R v Brown [1994] 1 AC 212, Lord Jauncey p246, Lord L Mustill pp272-275, Lord Slyn, p282.

3 R v Young [1866] 10 Cox CC 371

4 R v Coney [1882] 8 QBD.

5 British Medical Association. The boxing debate, 1993.

6 Roberts AH. Brain damage in boxers. London: Pitman, 1969:66-99.

7 Giovinazzo VJ, Yannuzzi LA, Sorenson JA, et al. The ocular complications of boxing. Ophthalmology 1987;94:587-960.

8 Cantu, R, ed. Boxing and medicine. Leeds: Human Kinetics, 1995:115-25.
} 


\section{Musculoskeletal change during spaceflight: a new view of an old problem}

Man has evolved in a one $G$ environment and our basic structure is designed to provide locomotion support in the world in which we live. It is thus a major transformation to live in the unique environment of space with its lack of gravity and the weightless state. ${ }^{1}$ Biomedical data from the US and Russian manned space programmes have made it clear that among other effects there are continuous and progressive changes in the musculoskeletal system. The most complete studies are those from the Apollo and Skylab programmes, in which bone mineral mass has been measured before and after flights of up to 84 days and inflight calcium balance has been studied. ${ }^{2}$ Measurements of the central os calcis, composed principally of trabecular bone, showed that bone loss increased in proportion to mission length, but the loss was not seen in the distal radius. Russian studies for up to 184 days showed losses of trabecular bone mass ranging from 0.9 to $19.4 \%$. Metabolic studies conducted on Skylab missions showed that urinary calcium content increased rapidly with a plateau after 30 days together with a small increase in faecal calcium loss. Over 84 days the average loss of calcium was $25 \mathrm{~g}$ from the overall body pool of about $1250 \mathrm{~g} .{ }^{3}$ Although some Russian reports have suggested that an extensive inflight exercise regimen may diminish calcium loss, this has not been the US experience.

The principal counter measures explored include various methods of weight loading, so as to provide movement against a fixed force, exercise, and nutritional or pharmacological manipulation. The crews of Skylab 3 and 4 exercised intensively during the 56 and 84 day flights respectively. Three of the six crew members showed substantial mineral loss, casting doubt upon the effectiveness of the particular exercise regimens. Similarly the Russian findings during long duration flights have not been consistent. Studies of some animals flown on the Cosmos Biosatelites and Spacelab on board the Space Shuttle also confirm skeletal changes. After 18 days, rats had a 30\% decrease in bone mechanical bending strength ${ }^{4}$; the loss of bone mineral in growing rats may be due to inhibition of bone formation rather than increased bone reabsorption.

Weight loss is a constant feature of manned space flight. Analysis of combined Apollo Skylab and Salyut data for flights of between 12 and 180 days suggests that weight loss averages up to $3-4 \%$ of the weight measured before a flight. These losses have been accompanied by a number of changes in muscle function, all of which suggest deterioration of muscle during flight. The negative nitrogen balance and biochemical pattern points strongly to muscle breakdown. ${ }^{6}$ This is reflected in a loss of muscle strength, about $10 \%$ in flexor muscles and $20 \%$ in extensor muscles of the leg. Again vigorous inflight exercise regimens did not prevent the loss of nitrogen, loss of muscle bulk, and diminution in strength. All the reported muscle and bone changes have occurred with no change in the serum concentration of appropriate regulatory hormones.

Recovery of the lost calcium and nitrogen begins soon after a return to earth. Calcaneal mineral lost is gradually replaced and this appears to take the same length of time as the $\operatorname{loss}^{7}$; however, it is variable - one Skylab astronaut had replaced only half his loss 90 days after the flight. Similarly, although long duration data suggested that calcaneal recovery was complete in a Russian study, spinal mineral loss was observed in cosmonauts six months after a flight. ${ }^{8}$ The most pronounced changes have been seen in weight bearing bones when mechanical stimulation appears to have a critical effect on bone structure and metabolism. ${ }^{9}$ Recovery of lost calcium and nitrogen is slow, with a positive balance only being established by 20 days after a flight.

Clearly these muscle and bone changes, if progressive, represent a real hazard to the weakened astronaut with fragile bones; the opportunities of using the unique properties of the space of the planetary environment for planned manufacturing processes or possible future lunar mining would be limited because of the significant risk to the wellbeing and efficiency of the astronaut. There is then the additional hazard of the effects of returning to earth and the substantial force of gravity.

Derangements of bone mineral metabolism are one of the major constraints to space flight. A complex set of stimuli are involved in the maintenance of skeletal integrity, the force exerted by attached muscles, forces exerted upon the longitudinal axis of bone by gravity, piezoelectric forces, and hydrostatic forces guaranteeing nutrient availability and waste disposal. Clearly musculoskeletal derangements will remain the focus of intensive investigation in the search for solutions to these real operational obstacles. Man has only recently entered space and some observers speculate that it could be as significant an event as when primaeval fish first crawled on to land. Certainly it offers a unique opportunity to study change in the absence of disease and to consider properly the effect of gravity on muscle and bone integrity. At present we have glimpses of the problem but no real answers. A clear conclusion is that gravity at the cellular level is a strong force which may be essential for efficient tissue synthesis. The relation between efficient muscle bulk and bone integrity may be worthy of particular consideration, and it is of interest that exercise regimens in the absence of gravity are at best of limited value.

All of this may appear to be remote from the world of the dedicated athlete where the training regimen is a hard task master and a dedicated lifestyle. It is, however, a possible pointer to the future, as, for example, if microgravity studies elucidate and quantify the basic relation between muscle size and bone integrity, then a more precise nutritional and exercise regimen may be particularly efficacious and sustaining.

ANTHONY GOODE

The Surgical Unit, St Bartholomews and The Royal London School of Medicine and Dentistry, London EC1, United Kingdom

1 Goode AW. Man in space. Nature 1980;23:525-6.

2 Rambaut PC, Goode AW. Skeletal changes during spaceflight. Lancet 1985; ii: $1050-2$.

3 Raumbaut PC, Johnston RS. Prolonged weightlessness and calcium loss in man. Acta Astronautica 1979;6:1113-22.

4 Gazenko OG, Ivin YEA, Genin AM. Principal results of physiological experiments with mammals aboard the cosmos 936 biosatellite. Space Biology and Aerospace Medicine 1980;14:33-7.

Doty SB. Morphagic and histochemical studies of bone cells from SL-3 rats. Physiologist 1985;28:379.

6 Leach CS, Rambaut PC. Biochemical responses of Skylab crewmen: an overview. In: Biochemical results from Skylab NASA-S P 377. Washington DC: US Government Printing Service, 1977:204-16.

7 Vogel JM, Whittle MW. Bone mineral changes. Aviat Space Environ Med 1976;47:396-400.

8 Cann C. Determination of spinal mineral density. Washington DC: Working Group: Space Biology and Medicine, 1981.

9 Hinsenilamp M, Burny F, Bourgois R. In vivo bone strain measurements. Aviat Space Environ Med 1981;52:95-103. 